\title{
How student beliefs about knowledge and knowing influence their satisfaction with assessment and feedback
}

\section{Introduction}

Prior research identifies students' beliefs about the nature of knowledge and knowing, frame how they interpret their educational experience and relate in complex ways to their approaches to, and perspectives on learning, teaching and assessment (Baxter Magolda 1992; Hofer 2004; Cano 2005; Lucas and Tan 2013). This paper draws on previous research identifying undergraduates' 'ways of knowing on entry to a UK post-92 university using an instrument developed by Baxter Magolda (1992) 'the measure of epistemological reflection'. Within data sets representing students categorised with particular ways of knowing, student views on assessment and feedback are investigated and discussed in relation to their epistemic assumptions. The paper subsequently considers the implications of these perspectives within the current context of higher education in which student views on, and satisfaction with, teaching and assessment have become increasingly influential.

\section{Epistemological beliefs and 'ways of knowing'}

The ground-breaking work of Perry (1970) characterises the intellectual development of college students as the development of their personal epistemological beliefs. Perry's research suggests students' beliefs about the nature of knowledge and its acquisition and form, change and develop in complexity and understanding over time. Later research in this complex area pays tribute to Perry's early work, often modelling such epistemological change, to a greater or lesser degree, as positional, staged and developmental. Within such development frameworks students' epistemic beliefs are considered to move from simplistic right/wrong judgements to more nuanced, contextual and pluralist perspectives. The beliefs of many new college students are depicted by Perry (1970) as 'dualistic' and by Belenky et al. as 'received' (1986), and 'absolute' by Baxter Magolda (1992). Students with such assumptions believe that there are correct answers that infallible authorities can reliably distinguish from those that are incorrect. However, as students develop intellectually their epistemic assumptions become increasingly relativist as students recognise the contestability of knowledge and the legitimacy of multiple perspectives (Perry 1970). Knowledge is seen as procedural and constructed rather than 
received (Belenky et al. 1986), contextual in nature (Baxter Magolda 1992) and increasingly complex (King and Kitchener 1994).

Here, it must be acknowledged that whilst many authorities pay homage to Perry's (1970) seminal research, there is considerable debate on how personal epistemology is conceptualised and developed in practice. Whilst much research situates students' epistemological perspectives within developmental frameworks, there are challenges to the notion of staged development. The influential work of Chickering (1969) views epistemological development as just one aspect of personal growth, and Schommer (1994) suggests five independent dimensions that are not, necessarily, progressively sequential. In Europe, research primarily has focused on 'conceptions of learning' (Saljo, 1982; van Rossum and Hamer, 2010). However, both Saljo (1982, chap. 12-13) and van Rossum and Hamer (2010, 125-126) argue that these conceptions are analogous to Perry's stages, and indeed, can be mapped on to Perry's (1970) developmental model.

That the core of epistemology involves the nature of knowledge and knowing is universally acknowledged. However, whether beliefs about teaching and assessment also constitute a legitimate part of investigations into students' personal epistemologies is subject to debate (Hofer and Pintrich 1997). Some authorities argue for a narrow definition of personal epistemology, limited to individuals' perspectives on the nature of knowledge and knowing (e.g. Sandolval 2009), others argue for a wider interpretation (e.g. Baxter Magolda 2004; Elby 2009). Whilst the nature of the interrelationship between students' epistemological beliefs, learning approaches and assessed performance requires further investigation, many researchers highlight a significant association between such beliefs and student approaches to, and perspectives on learning, teaching and assessment (see for instance Baxter Magolda 1992; Hofer 2004; Cano 2005; Lucas and Tan 2013). Indeed, Elby (2009) suggests there is an inseparable entanglement between individuals' views on knowledge and their perspectives on learning and teaching, and that many researchers in this area are concerned with views about knowledge because of their influence on student learning.

\section{Student Satisfaction}

Student satisfaction matters, and arguably matters more than ever within an increasingly competitive and commercial higher education sector. Arambewela and Hall $(2013,1)$ amongst 
others argue that nowadays to attract and retain students, universities are 'compelled to pursue market orientation strategies placing greater emphasis on meeting student expectations'. One such strategy is the ubiquitous use of surveys across the international sector to measure student perspectives on, and satisfaction with, their higher education experience with the intention to both communicate educational quality to prospective students and underpin managerial decision-making (Bedggood and Donovan 2012). The UK is no exception: the National Student Survey (NSS) and Key Information Sets (KIS), in which student perspectives on the quality of higher education is emphasised, make data on undergraduate provision available to all stakeholders. According to the UK National Union of Students NSS results have compelled UK institutions to make positive changes to the student experience including improvements to assessment and feedback practices (NUS 2008). Gibbs claims that UK institutional and departmental processes and behaviours are now being driven by such data to 'an unprecedented extent', but cautions that measures of student satisfaction are not always good indicators of educational quality (Gibbs 2010,14). Concerns over the reliability and validity of student satisfaction as a measure of quality (Gibbs 2010; Bedggood and Donovan 2012) and anxiety about students giving high evaluation ratings to teachers who challenge them the least or give undeserved high marks (Scott, 1999; Kuh 2003, Gibbs, 2010) are widespread both in the UK and internationally. Many educational theorists posit that learners construct reality and "evolve through eras according to regular principles of stability and change" (Kegan 1982, p. 8). Often arguing that learning is likely to be uncomfortable during the cycles of change as learners' meaning schemes are disrupted within a process of change and development (Kegan, 1982, 8; Baxter Magolda, 1992, chap. 1; Meyer and Land, 2005, 376). Nevertheless, the commercial imperative to enhance student satisfaction with their university experience is increasingly accepted across the international higher education sector. However, identifying what this entails still requires further work (Guolla, 1999; Mark, 2013).

Quality in higher education service provision is a complex and multi-faceted concept, and the relationship between perceptions of service quality and student satisfaction still ambiguous (Annamdevula \& Bellamkonda, 2016). However, many authorities within the services marketing literature (see for instance: Cronin and Taylor, 1992; lacobucci et al., 1995; Dabholkar et al., 2000) consider service quality as antecedent to customer satisfaction. Within the sphere of higher education Guolla (1999) and Ahmed et al. (2000) agree, regarding service quality as leading to student satisfaction. The services marketing literature generally suggests that 
customers are considered to be satisfied when the quality of service they receive matches or exceeds their expectations (see for instance: Hill, 1995; Munteanu et al, 2010). Elliott and Shin $(2002,199)$ state that in the context of higher education student satisfaction is when 'perceived performance meets or exceeds the student's expectations'. Based on her longitudinal research into students 'ways of knowing', Baxter Magolda asserts that student perspectives on the role and nature of teaching and assessment are inextricably intertwined with students' epistemic assumptions about the nature and certainty of knowledge (Baxter Magolda, 1992). In light of the increasing importance of student satisfaction it is therefore valuable to understand what students' expect from their university experience and how these perspectives link with their epistemic beliefs.

\section{Research context and objectives}

Within an increasingly competitive environment, the Business Faculty of a post-92 UK university planned significant structural changes, including undergraduate course redesign, to boost the attractiveness of, and student satisfaction with, its provision. During the run-up to the restructure Faculty staff engaged in lively debate over the nature and purpose of business education, questioning what undergraduates were gaining from their learning experience and in particular the role and value of assessment. The latter discussion was prompted by student perspectives on the quality of assessment and feedback provision remaining intransigently low, despite a plethora of enhancement activity in this area. Consequently, this study involves insider research undertaken by a practitioner researcher with an unashamed enhancement agenda orientated toward exploring and improving both assessment and feedback practice and students' perceptions of its quality. Bensimon et al. $(2004,105)$ suggest that it is important for practitioners focused on organisational enhancement to 'produce knowledge in local contexts to identify problems and take action to solve them' advocating 'practitioners as researchers'. The study draws on outcomes of prior research that identified students' epistemological beliefs, to focus on deeper exploration of the relationship of these beliefs with student expectations, perspectives and satisfaction with assessment and feedback. 


\section{Method}

The study draws on prior research (O'Donovan, 2010) that identified the epistemological beliefs of new undergraduates on entry to a business and management degree using an instrument designed by Baxter Magolda (1992) 'the Measure of Epistemological Reflection' (MER). Originally developed for the US, the MER is a research instrument that seeks to determine students' assumptions in five core domains: role as a learner; role of peers; role of tutors; role of assessment; and beliefs about the nature of knowledge. Baxter Magolda expresses these assumptions as students' 'ways of knowing', a term she explains as follows:

Students interpret, or make meaning of, their educational experience as a result of their assumptions about the nature, limits, and certainty of knowledge. Such assumptions referred to by researchers as epistemic assumptions, collectively form 'ways of knowing.

Baxter Magolda $(1992,3)$

The MER instrument involves open-ended questions that ask respondents to state their perspectives on introductory statements and then further elaborate on their reasoning in followup questions. For brevity only the questions focused directly on assessment and feedback are reproduced here.

\section{Measure of epistemological reflection (MER) -- assessment and feedback questions}

Some people think that hard work and effort will result in high marks in school. Others think that hard work and effort are not a basis for high grades. Which of these statements is most like your own opinion?

Ideally, what do you think should be used as basis for evaluating your work in college courses?

Who should be involved in the evaluation you described above?

Please explain why you think the response you suggested above is the best way to evaluate students' work in college courses?

(Baxter Magolda, 1992, 425).

Students' ways of knowing, previously published (O'Donovan, 2010), are briefly summarised here along with an account of the data analysis to aid conviction in the categorisation process. 
Two hundred responses from undergraduates on entry to a business and management degree programme were analysed. Responses represented 101 female and 99 male participants, 68 of which were international from 36 nationalities with the highest representation from the UK (104) and China (30). Participants were largely school leavers with only 19 considered 'mature learners' (over 21 years of age). In the UK most students leave home to go to university, living in university halls of residence in their first year, and these students were no exception, 179 out of the 200 were 'in halls'.

The analysis was undertaken by two researchers using training materials provided by Baxter Magolda, and the student's reasoning in each domain identified. The analysts found it relatively straightforward, if time consuming, to categorise students and the MER seemingly translated easily to the UK context (with a few changes in nomenclature, e.g. 'university' rather than 'college'). Here, it should be noted that whilst the training materials provided by Baxter Magolda outlined a constructivist interpretation process, the analysts overlaid this with, frankly, a more positivist approach which focused on rating students against written responses to the MER questions, rather than dialogic interviews. Similar to Baxter Magolda's research in the US (1992), the vast majority of students were rated as 'absolute' (91) or 'transitional' (84). Learners with absolute ways of knowing assume knowledge to be certain, either right or wrong, with differences between authorities attributed to misinformation or misunderstandings. 'Taught' knowledge is valued in terms of incontestable facts and demonstrable theories. Students interpreted as transitional began to view knowledge as less certain in some contexts, often attributing this variation to subject differences. Again aligning with Baxter Magolda's own research (1992), there were few students presenting 'independent' (21) or 'contextual' (4) ways of knowing. Students' exhibiting an independent way of knowing present a fundamental shift in beliefs, acknowledging the contestability and uncertainty of knowledge. But within this uncertainty, these learners have no system for evaluating the relative strength of knowledge claims, their own beliefs and opinions often being regarded as valid as that of an authority. The four students categorised as exhibiting a contextual way of knowing also recognised the uncertainty and contestability of knowledge claims, but evaluated these claims in relation to the context in which they were made.

It is useful to highlight here that the classification of a student's stage of development represents an overall assessment of an individual student's way of knowing. However, within 
this overarching classification students may exhibit different stages of knowing in different domains. For example, a student classified as Absolutist might demonstrate some Transitional tendencies in one or two of the domains. Academics involved in the marking of assignments with rubrics representing multiple criteria may find such overall grading familiar practice. An assignment graded as a B may have some attributes considered to be at an A grade of achievement and others at a $\mathrm{C}$ grade. The final classification is therefore not solely determined by a mechanistic addition of domain categories but involves a holistic judgment of a response. Saljo (1988) reminds us that the categories of description are constructed and interpreted by researchers. However, whilst responses were not numerically rated, and no quantitative interrater reliability score determined, categorisations were subsequently discussed by the two analysts to support the dependability of analysis. Kvale describes this as 'agreement through rational discourse and reciprocal technique' (1996, 65).

Such beliefs were perhaps predictable -- after all students were categorised as having particular ways of knowing because they reported such beliefs! Arguably, of more interest and recounted here, is richer exploration of students' expectations and views on assessment and feedback. Thematic analysis of the data was subsequently undertaken manually by one researcher over a two-year period to gain deeper understandings. Whilst thematic analysis is a widely used qualitative analytical method it has been criticised for often being poorly demarcated (Braun and Clarke, 2006). Consequently, detail on how the analysis was undertaken is provided here. The corpus of student responses was initially divided into data sets representing the final classification of students' way of knowing (i.e. 'absolute', 'transitional', etc.), then each re-read within these classifications to identify the themes and patterns of students' perspectives on assessment and feedback across each data set. Coding and theme development within each classification was inductive, and directed by the content of the data. Initially, only the responses to the assessment questions on the MER were re-examined. However as a number of students commented on assessment and feedback across the MER (i.e. not just in response to direct questions on assessment) the entire questionnaires were re-read. Subsequently on further rereading, comments on assessment and feedback were highlighted and associated with descriptive codes (e.g. comments about assessment marks or fairness) for each data set in turn. These descriptive codes were closely read and re-read and progressively refined and then interpreted into themes. Themes are generally semantic, descriptive of student perspectives, and given conviction and voice through the use of multiple quotes 
Interestingly in this second stage of data analysis, students rated as having 'transitional' or 'absolute' ways of knowing presented largely similar perspectives on assessment and feedback, as did those few students with 'contextual' and 'independent' ways of knowing. However, student perspectives about assessment and feedback were notably very divergent between these two aggregated groupings. As such findings are for the most part presented within two groups: 'absolutist/dualistic' representing those students identified as exhibiting absolute or transitional ways of knowing and 'pluralistic' representing those few students identified as exhibiting contextual or independent ways of knowing. Where differences did emerge, e.g. between absolute and transitional, these are highlighted and discussed.

\section{Findings}

\section{Assessment and feedback constructs of 'absolute' (91) and 'transitional' knowers (84)}

Instrumentality: good teaching as effective assessment preparation

That assessment is a key driver of student learning behaviour is well evidenced (see for instance Ramsden 1992; Rust, Price, and O'Donovan 2003). However, it was still surprising just how much students wrote on assessment. Students were keen to communicate in detail how best to assess their work, and the space for four/five lines of handwriting under each question in this domain was insufficient for many, with handwritten responses being squeezed in and margins used. In addition, much that was written by absolute and transitional knowers in response to questions on the role of tutors and teaching was contextualised in terms of effective preparation for assessment. A strong theme was the importance of getting a high mark and thereby the need to identify the 'key points' required in assessment and the clarification of these in class through 'good teaching'. Good teaching being considered primarily by students as when tutors focus on 'teaching to the test' and use effective memorisation techniques that result in higher marks. Students exemplified techniques perceived as effective using their experiences from secondary education. Indeed, there was a strong undertone of polite advice on how other teachers could go about imitating these practices.

Good teaching is making sure everyone knows and remembers enough to do well in the exam, don't leave anything to chance [18yrs, male, UK] 
The teacher used to make us chant important facts at school, it really helped me remember the important stuff [18yrs, female, UK]

My A Level [final secondary school examinations] teacher was excellent, he was clear about the facts that students should know for the exam and made sure that we knew them with lots of examples and practice [18yrs, female, UK]

\section{'Good students' should be rewarded by their tutors: it's only fair}

Students' exhibiting absolute or transitional perspectives considered effort should be rewarded as well as outcomes. They wanted expert tutors to assess their work, but who also knew that they were 'good students' (explained in terms of their preparation for, attending and participation in class) so that their diligence and effort could be rewarded. For many it seemed unfair to achieve a high mark without regularly attending class. An underpinning sub-theme was 'fairness', expressed in terms of clarity of assessment expectations and requirements as well as rewarding 'good student behaviour'.

Students may not be successful in a piece of work but may have tried really hard which has to be worth something [18yrs, male, Ukraine]

Effort should be rewarded. I want my work marked by someone who knows I have been in class and tried hard. It's not fair if someone gets good marks who hasn't been coming to class or doing the work [18yrs, female, UK]

\section{Assessors should know the student whose work they are marking}

Perhaps in part because many students thought effort and good student behaviours should be rewarded, absolute and transitional students desired an assessor who knew them:

Teachers who know that you have tried your best to be a good student [19yrs, male, China] Very important for a teacher to mark who knows his student makes effort and tries hard [18yrs, female, Zimbabwe]

Seminar tutors who can judge how much a student put effort and is willing to study and be a good student [22yrs, female, UK] 


\section{Authority dependence and irrelevance of peer input}

Students with absolute and transitional ways of knowing were very concerned about the suggestion that anybody but an 'authority' should mark their work. Indeed, many referred to a course guide that detailed an upcoming peer review initiative with considerable anxiety and a few, polite, reminders that assessment forms part of the paid work of teaching staff.

I am worried that you are asking us how we should be assessed. The teacher evaluates what we have learnt. What other way can there be? [18yrs, male, Venezuela]

The teacher is the expert, not the students and should mark work. [18yrs, female, Nigeria] It's the tutor's work to mark students work. It's part of their work [19yrs, male, UK] I go to class to get info, not to give info [18yrs, male, UK]

\section{Feedback as specific and corrective}

Good feedback was seen as specific and corrective. Indeed, getting facts, techniques and perspectives 'correct' was a frequently used expression aligning with dualistic epistemic assumptions and the presumption of a single model answer.

Uni is new to me and I need to know how I am doing by having my work corrected [19yrs, female, Taiwan]

The teacher needs to correct work so we know our mistakes [18yrs, female, Poland] I want to know that I am doing my work correctly [18yrs, male, UK]

\section{Expectation of absolute clarity on assessment requirements, standards and criteria}

The line between 'absolute' and 'transitional' knowing is blurred. Transitional knowers held many of the same assumptions as absolute/dualist knowers, but viewed knowledge as absolute in some subjects but uncertain in others. In answer to a question on whether there could be two differing but valid explanations for the same phenomenon, students with transitional perspectives acknowledged that this could be the case in some subjects.

I liked my A level exams because it is was clear the key points you needed to know to get the marks but it is different at university particularly in some subjects. [18yrs, male, UK] 
I $\operatorname{did} \mathrm{A}$ level chemistry and things are more straightforward and right than in business studies [19yrs, female, UK]

Students with absolute ways of knowing suggested that there was always one right answer and where evidence was contradictory expert teachers should know and 'teach' the right answer.

How should I know which explanation is wrong or right? I just hope the tutor studies enough as well. [18yrs, male, UK]

She [the tutor] needs to find out the right info and make sure we know it. All this 'he says this but he says that' is a time waster it is better to give a straight answer [18yrs, male, UK]

Students exhibiting absolute and transitional ways of knowing both wanted 'absolute' clarity on what was expected in assessment and their own achievement. However, underpinning this desire there appeared to be a more nuanced difference in terms of the legitimacy of variation between marking criteria, assessment requirements and standards between subjects. Many transitional students seemingly accepted that these could legitimately vary across subjects but still expected that standards and marking criteria both should and could be clarified completely. Absolute students were more likely to see such variation as illegitimate and symptomatic of poor, inconsistent teaching and assessment and thereby sought both clarity and consistency:

With regular tests a teacher can see if students are having a problem with a particular subject especially if it is new to them [Transitional, 18yrs, female, UK]

I need to know what is expected in each subject so I can write what how each subject wants me to write [Transitional, 18yrs, female, China]

There may be no right answers in some subjects but they should all say the same thing so as not to confuse students before the exam if they want students to do well [Absolute, 19yrs, female, US]

All I know is everyone needs to say the same. We need to know what is expected of us in terms of essay and exam writing... teachers must be very clear about what they want me to write. My history [A level?] teacher was hopeless [Absolute, 19yrs, female, UK]

Business studies is not satisfactory, too much discussion can be muddling, teach what we need to learn to do well like accounting (Absolute, 18yrs, male, UK] 


\section{Assessment and feedback constructs of 'independent'(21) and 'contextual'(4) knowers}

The 25 (12.5\%) students classified with independent or contextual ways of knowing presented similar views on assessment and feedback but starkly different beliefs from those students with absolute and transitional ways of knowing.

Assessment should involve more than one marker in discussion with the student

Perhaps because they recognised different perspectives could be taken on a piece of work and that assessment was not such a straightforward right/wrong process, students considered that their work should be assessed by more than one marker and that they should be included in this process to explain and defend their work.

Assessment and feedback should be an interactive process with the teacher and student [18yrs, female, UK]

Relevant tutors mainly, [should assess] though student input may be beneficial so I can explain why I have written the essay in a certain way [18yrs, male, Poland]

I would like to have my work evaluated by more than one marker, it would make me feel like I was being graded fairly [19yrs, female, Germany]

\section{Assessment as a relational process}

Like the absolute and transitional students, those students exhibiting independent and contextual knowing wanted their work to be marked by a tutor whom they knew and who knew them. However, at this stage this was not to recognise and reward effort, but so their work could be judged within their personal context including knowledge of their prior work. This was sometimes considered to be their 'personal tutor' (a lecturer supporting a student throughout their degree in terms of academic advice and pastoral support). In answer to 'who should be involved in assessment', responses included:

The teacher/lecturer I suppose, but how does she/he know who 'I AM' [student's own capitalisation] there's so many of us [18yrs, male, UK]

Your personal tutor should be involved in assessment so they can judge your overall progress and if there are inconsistencies [22yrs, male, UK] 
Personal tutors who know you and can track your progress over the degree [19yrs, female, Serbia]

\section{Feedback as dialogue}

Assessment and feedback were generally seen as intertwined and, at their best, dialogic. Students hoped to be able to discuss their work with their tutors. Arguably the desire to discuss work with assessors seems understandable in contexts where knowledge is viewed as contestable, nuanced and relativistic.

Personal tutors and module leaders should mark and feedback on work in discussion with students [18yrs, male, Greek]

At this level I hope to discuss my work with tutors not just get a few lines" [of feedback], [19yrs, male, UK]

Teachers and pupils need to discuss together to a certain extent to see where improvements could be made etc. [18yrs, female, German]

\section{Appreciation of subject variation and the legitimacy of assessment variation}

Students exhibiting independent and contextual/pluralist ways of knowing appeared to view disciplinary variation as legitimate and thereby differences in knowledge structures, assessment standards and marking criteria.

We had [secondary education] more essays to do in history than chemistry. I prefer coursework to exams but understand that exams are better for sciences [19yrs, female, UK]

I'm doing Business with Maths and they are so different and shouldn't be assessed on the same basis (20yrs, male, China)

One student exhibiting contextual knowing speculated that this variation could be helpful to their learning.

I did a Baccalaureate before coming to Uni including theory of knowledge, doing a lot of different subjects helps you understand how they differ and do better in each [18yrs, male, UK] 


\section{Discussion}

Prior research demonstrates that the beliefs of students on the nature of knowledge and knowing influence their perspectives on learning, teaching and assessment (Baxter Magolda 1992; Hofer 2004; O'Donovan 2010: Lucas and Tan 2013). The intention of this study is to gain a richer understanding of perspectives on assessment and feedback characteristic of groups of students with fundamentally different epistemic assumptions and to tease out the implications for student satisfaction. Such a focus is anticipated to be of interest as firstly, student perspectives on their experience increasingly find expression in student experience surveys (Bedggood and Donovan 2012; Dean and Gibbs 2015). Secondly, such survey results drive institutional and departmental behaviours in the endeavour to enhance educational quality (Gibbs 2010), and 'satisfy' students (Tsinidou, Gerogiannis, and Fitsilis 2010).

Aligning with much prior research the majority of students in this study came to university with absolute/dualist belief systems. Consistent with these beliefs was a high regard for teaching and assessment approaches that value memorisation and the recitation of facts. Students valued reproductive assessment and viewed 'good teaching' as effective assessment preparation. In this study $176(n=200)$ of students came directly from secondary school or after a 'gap-year' usually consisting of work and travel, and their assessment expectations will have been shaped by their secondary school experiences. Within UK education it has been argued that increased national testing throughout the school years has resulted in teachers spending substantial time preparing students for tests (Sturman, 2003), and compelled students to concentrate on memorisation behaviours (Boyle and Bragg, 2006), a situation echoed in the United States (Nelson, 2012; Brimi, 2013). Consequently, it is perhaps unsurprising that students arrive already conditioned into reproductive learning approaches and anticipating more of the same.

A progressive intensification of student instrumentality within higher education, in terms of the attainment of marks and 'good degrees' has also been highlighted by scholars over the last two decades (e.g. Ramsden, 1992; Kember 2001; Dean and Gibbs 2015). Perhaps this is unsurprising as it is such marks that largely win students a place at university, and determine their degree awards and employment prospects (Snowden 2012). Consequently, it is understandable that students' demand for 'good' assessment and feedback practices has 
become more insistent. The issue here is arguably not about the intensification of student demands, but their nature in terms of their perspectives on what constitutes good quality assessment and feedback practice. In this study the majority of students held dualistic assumptions and viewed good assessment and feedback practices as unambiguous and clear. They valued explicit assessment requirements with marking criteria that clearly detailed the 'one best way' of responding to an assessment task. Upon submission students wanted their work to be objectively and reliably marked by experts and returned with unequivocal, corrective feedback. However, whether these demands can be met, or indeed, should be met is more debateable.

In the UK, the ubiquitous 'National Student Survey' asks final-year undergraduates to agree or disagree to various extent with five statements on assessment and feedback, including: 'the criteria used in marking have been made clear in advance'; I have received detailed comments on my work', and; 'feedback on my work has helped me clarify things I did not understand'. How students respond to these statements will depend on their epistemic assumptions and, indeed, whether they can be realised in some academic contexts. Explicit articulation of assessment standards and criteria can be challenging due to the tacit nature of standards, and multiple interpretations of marking criteria (O'Donovan, Price, and Rust 2004). It may also be problematic, for example, to clarify the nature of effective argumentation within written feedback in tentative, complex and pluralist subject areas. In such circumstances, unless dialogic and well resourced, feedback may do little more than diagnose and describe the nature of any issues or shortcomings (Price et al. 2010). However, where feedback is oral and dialogic (in tutorials for example) some research suggests that students understandably view this not as 'feedback' but as 'teaching' (Ashwin 2005). Nevertheless, previous studies suggest that student demands for specific and corrective feedback are often met within the first year of university. Dualist assumptions may be affirmed through pedagogies and assessments in large introductory classes, such as lectures and multiple-choice tests, which focus on knowledge acquisition and emphasise 'learning of established facts and demonstrable theories, rather than uncertainties and relativities' (Nyman and Berry 2002, 407). Indeed, Gibbs suggests 'even when lecturers say that they want students to be creative and thoughtful, students often recognise that what is really necessary, or at least what is sufficient, is to memorise' (Gibbs 1992, 10).

An initial focus on declarative knowledge can, in part, be explained in terms of the hierarchical knowledge structures of some subjects where certain facts and evidential theories may need to 
be acquired before meaning can be made (Bernstein 1999). Indeed, within a neoliberal higher education sector there may be risks in encouraging new undergraduates to question their epistemic assumptions. As Kember (2001) suggests, intellectual development requires challenging the belief systems of students thereby potentially creating discomfort. Even shortlived student discomfort may be 'risky' in a context where universities are viewed and judged as service providers. Indeed, resistance and initial dislike of innovative and discursive forms of teaching by the majority of students has long been cited as a reason for sticking to didactic teaching methods (McKay and Kember 1997), and deterring tutors from challenging the belief systems of students (Kolitch and Dean 1999). This is understandable within contexts where an increasing emphasis on student satisfaction and instructor evaluations, along with publication profiles, are considered the 'de facto gold standard of retention, tenure and promotion decisions' (Gerstman 1995, 122). An overemphasis on student satisfaction can endorse a consumerist perspective in which student views become paramount (Harvey, 1995), and the oversimplification of difficult knowledge areas can hold back students from understanding significant concepts (Shanahan and Meyer 2006). A situation that may not only accommodate, but entrench more naïve epistemological positions. Indeed, Gow and Kember (1990) note that it can be seen as an achievement if students' learning approaches do not decline.

Findings demonstrate both sets of students as keen to know and be known to their assessors. Students with dualistic beliefs wanted their effort and diligence to be taken into account. Relativist students wanted to be involved in the assessment of their work to enable explanation and defence of their viewpoints, and perhaps knowing that different perspectives could be taken on an assignment, to ensure closer alignment of their assessment response with the perspectives of individual markers. Whilst there has been little empirical research in this area, researchers have argued for enhancing dialogue in assessment and feedback practice to underpin student learning, and that anonymous marking can hinder staff from writing tailored feedback to suit the developmental needs of the student (Price et al., 2010). However, with the massification of higher education, tighter resources and calls for more objective and anonymous marking, for example by the UK Quality Assurance Agency (QAA 2006) and the National Union of Students (NUS 2008), more relational, dialogic approaches to assessment and feedback seem less, rather than more likely in the future. 
The final two assessment statements in the UK's National Student Survey focus on assessment fairness and feedback promptness ('assessment arrangements and marking have been fair' and 'feedback on my work has been prompt'). In this study, interestingly, promptness of feedback was not highlighted by students as significant, however, fairness was a significant theme. Depending on their epistemological beliefs students held different interpretations on what made assessment 'fair'. Students exhibiting dualistic beliefs tended to expect fair assessment to adhere to objective, reliable, and consistent marking and yet take their effort into account. Within a belief system in which work is considered either correct or not, and markers to hold a model answer against which work can be uniformly judged, consistent and reliable marking appears easily attainable and therefore to be expected. Accordingly it is perhaps understandable that a student would consider it 'unfair', or indeed unsatisfactory, if consistency is not achieved. Students holding relativist beliefs accepted a more nuanced and subjective understanding of marking standards and criteria. However, because of this acceptance they considered it important that individual markers' perspectives were known prior to assessment and that, as part of the marking process, they would have the time and space to explain and defend their work.

Students exhibiting dualistic beliefs found different disciplinary approaches to assessment design and standards representative of chaotic inconsistency. It is suggested that perceptions of assessment quality emanate from the epistemic assumptions of disciplines in terms of accepted concepts, knowledge structures, methods and marking criteria (Donald 2009). Even within an academic department or course of study epistemic assumptions can vary. Indeed, Lattuca suggests it is naive to assume that many departments 'share areas of interest, methods, or even epistemological perspectives' (2001, 3). Business and management may be considered particularly problematic in this regard as it is inherently 'multidisciplinary in nature' involving the coexistence of multiple disciplines often with little or no interaction between them (Ryan and Neumann 2013, 195). Accordingly, it perhaps behoves teaching academics, not only to be more explicit about the varied epistemic assumptions in play, but also to develop strategies for students to be able to manage this variation, not with a view to achieve epistemological consistency but for students to better understand and be able to cope with epistemic variation across a programme. Goodyear and Ellis $(2007,65)$ argue that students draw benefit from induction to more than one epistemic community, but found 'very few signs of teachers inducting students into ways of knowing and thinking characteristic of their discipline or profession', and indeed in terms of tutor understandings 'no traces of language showing a nuanced 
understanding of epistemic activity'. Van Rossum and Hamer (2010, chap. 5) concur, stating few teachers have sophisticated understandings of knowledge and learning, Further research into both this area and the relationship between students' epistemic assumptions and their evaluation of their higher education experience may provide a way forward to resolve the tensions between student satisfaction and teaching and assessment practices that encourage movement towards relativism.

\section{Conclusion}

Student evaluation of their assessment and feedback experience is becoming increasingly influential. It is not surprising that epistemic assumptions strongly affect student views on and thereby their satisfaction with assessment and feedback. It may also be unsurprising to those who teach undergraduates that the majority of new students want assessment standards and criteria to be unambiguous and explicit and feedback specific and corrective. Faced with assessment tasks that move beyond established facts and evidential theories it may be only students who view knowledge as relative and mutable that will likely be 'satisfied' with their assessment and feedback experience. Whilst educational quality is inextricably linked to student evaluation of, and satisfaction with, higher education service quality (Tsinidou, Gerogiannis, and Fitsilis 2010), they are not the same (Gibbs, 2010). This is not to decry the burgeoning influence of the student voice on their university experience, but to suggest that we should be careful in our response to it lest through abjuring any signs of discomfort or dissatisfaction we also undermine the very intellectual development we seek to support. Faced with this dilemma it may behove teaching academics to refocus assessment and feedback enhancements away from the traditional emphasis on improving techniques and processes to sharing and developing understandings of the epistemic assumptions implicit in disciplines, assessment tasks and held by students and staff. This may not only enhance student learning (Brownlee et al. 2009) but also their satisfaction with their assessment and feedback experiences. 


\section{References}

Ahmed, I., Nawaz, M. M., Ahmad, Z., Ahmad, Z., Shaukat, M.Z., Usman, A., Rehman, W. and Ahmed, N. (2000). Does service quality affect students' performance? Evidence from institutes of higher learning. African Journal of Business Management, 4(12), 2527-2533.

Annamdevula, S. \& Bellamkonda, R.S. (2016). The effects of service quality on student loyalty: the mediating role of student satisfaction. Journal of Modelling in Management, 11(2), 446 462, doi:10.1108/JM2-04-2014-0031

Arambewela, R., \& Hall, J. (2013). The interactional effects of the internal and external university environment, and the influence of personal values, on satisfaction among international postgraduate students. Studies in Higher Education, 38(7), 972-988, doi:10.1080/03075079.2011.615916

Ashwin, P. (2005). Variation in students' experiences of the Oxford tutorial. Higher Education, 50(4), 631-644, doi:10.1007/s10734-004-6369-6

Baxter Magolda, M.B. (1992). Knowing and reasoning in college: gender-related patterns in students' intellectual development. San Francisco, CA: Jossey-Bass.

Baxter Magolda, M.B. (2004). Evolution of a Constructivist Conceptualization of Epistemological Reflection. Educational Psychologist, 39(1), 31-42, doi:10.1207/s15326985ep3901_4

Bedggood, R. E., \& Donovan, J. (2012). University Performance Evaluations: What are we really measuring? Studies in Higher Education, 37(7), 825-842, doi:10.1080/03075079.2010.549221

Belenky, M.F., Clinchy, B. M., Goldberger, N. R., \& Tarule, J.M. (1986). Women's ways of knowing: the development of self, voice and mind. New York: Basic Books.

Bernstein, B. (1999). Vertical and horizontal discourse: An essay. British Journal of Sociology of Education, 20(2), 157-173, doi:10.1080/01425699995380

Bensimon, E. M., Polkinghorne, D. E., Bauman, G., \& E. Vallejo. (2004). Doing research that makes a difference. The Journal of Higher Education, 75(1), 104-126, doi:10.1353/jhe.2003.0048 
Boyle, B., \& Bragg, J. (2006). A curriculum without foundation. British Educational Research Journal, 32, 569-582. doi:10.1080/01411920600775225

Braun V. \& Clarke V. (2006). Using thematic analysis in psychology. Qualitative Research in Psychology, 3(2):77-101, doi:10.1191/1478088706qp063oa

Brimi, H. (2012). Teaching writing in the shadow of standardized writing assessment: An exploratory study. American Secondary Education, 41(1), 52-78.

Brownlee, J., Walker, S., Lennox, S., Exley, B., Pearce, S. (2009). The first year university experience: using personal epistemology to understand effective learning and teaching in higher education. Higher Education, 58 (5), 599-618. doi:10.1007/s10734-009-9212-2

Cano, F. (2005). Epistemological beliefs, approaches to learning, and academic performance. British Journal of Educational Psychology, 75, 44-57, doi:10.1348/000709904X22683

Chickering, A. W. (1969). Education and Identity, San Francisco: Jossey-Bass.

Cronin, J.J. Jr. \& Taylor, S.A. (1992). Measuring service quality: a re-examination and extension, Journal of Marketing, (56)3, 55-68, doi:10.2307/1252296

Dabholkar, P.A., Shepherd, C.D. \& Thrope, D.I. (2000). A comprehensive framework for service quality: an investigation of critical conceptual and measurement issues through a longitudinal study. Journal of Retailing, 76(2), 131-139, doi:10.1016/S0022-4359(00)00029-4

Dean, A. \& Gibbs, P. (2015). Student satisfaction or happiness?: A preliminary rethink of what is important in the student experience. Quality Assurance in Education, (23)1, 5-19, doi:102013-0044

Donald, J. G. (2009). The Commons: Disciplinary and Interdisciplinary Encounters. In C. Kreber (Ed), The University and its Disciplines (pp.181-195). New York: Routledge.

Elby, A. (2009). Defining Personal Epistemology: A Response to Hofer \& Pintrich (1997) and Sandoval (2005). Journal of the Learning Sciences, 18(1): 138-149. doi:10.1080/10508400802581684

Elliott, K.M, \& Shin, D. (2002). Student satisfaction: An alternative approach to assessing this important concept. Journal of Higher Education Policy and Management, 24, 197-209, doi:10.1080/1360080022000013518 
Gerstman, B. (1995). Student evaluations of teacher effectiveness: the interpretation of observational data and the principle of faute de mieux. Journal of Excellence in College Teaching, 6(3), 115-124.

Gibbs, G. (1992). Improving the quality of student learning. Bristol: TES.

Gibbs, G. (2010). Dimensions of quality. York: Higher Education Academy.

Goodyear, P. \& Ellis, R. (2007). The development of epistemic fluency: Learning to think for a living. In A. Brew \& J. Sachs (Eds.), Transforming a university: the scholarship of teaching and learning in practice (pp. 57-68). Sydney: Sydney University Press.

Gow, L. \& Kember, D. (1990). Does higher education promote independent learning? Higher Education, 19(3), 307-3, doi:10.1007/BF00133895

Guolla, M. (1999). Assessing the teaching quality to student satisfaction relationship: applied customer satisfaction research in the classroom. Journal of Marketing Theory and Practice (7)3, 87-97, doi:10696679.1999.11501843

Harvey, L. (1995). Keeping the customer satisfied: The student satisfaction approach. University of Central England: QHE.

Hill, F. (1995). Managing service quality in higher education: the role of the student as primary consumer. Quality Assurance in Education, (3)3, 10-21, doi:10.1108/09684889510093497

Hofer, B.K. (2004). Exploring the dimensions of personal epistemology in different classroom contexts: Student interpretations in the first year of college. Contemporary Educational Psychology, 29(2), 129-163, doi:10.1016/j.cedpsych.2004.01.002

Hofer, B. K., \& Pintrich, P.R. (1997). The development of epistemological theories: Beliefs about knowledge and knowing and their relation to learning. Review of Educational Research, 67(1), 88-140, doi:10.3102/00346543067001088

lacobucci, D., Ostrom, A. \& Grayson, K. (1995). Distinguishing service quality and customer satisfaction: the voice of the customer. Journal of Consumer Psychology, (4)3, 277-303, doi:10.1207/s15327663jcp0403_04

Kegan, R. (1982). The evolving self: problem and process in human development. Cambridge, MA: Harvard University Press. 
Kember, D. (2001). Beliefs about Knowledge and the Process of Teaching and Learning as a Factor in Adjusting to Study in Higher Education. Studies in Higher Education, 26(2), 205221. doi:10.1080/03075070120052116

King, P. M., \& Kitchener, K.S. (1994). Developing reflective judgement. San Francisco: JosseyBass.

Kolitch, E., \& Dean, A.V. (1999). Student Ratings of Instruction in the USA: hidden assumptions and missing conceptions about 'good teaching. Studies in Higher Education, 24(1), 27-42. doi:1080/03075079912331380128

Kuh, G. D. (2003). What we're learning about student engagement from NSSE. Change Management, March/April, 24-32.

Kvale, S. (1996). An introduction to qualitative research interviewing. Thousand Oaks: Sage.

Lattuca, L. (2001). Creating Interdisciplinarity. Nashville: Vanderbilt University Press.

Lucas, U., \& Tan, P.L. (2013). Developing a capacity to engage in critical reflection: students 'ways of knowing' within an undergraduate business and accountancy programme. Studies in Higher Education, 38(1), 104-123. doi:10.1080/03075079.2011.569706

McKay, J., \& Kember, D. (1997). Spoonfeeding leads to regurgitation: a better diet can result in more digestible learning outcomes. Higher Education, Research and Development, 16(1), 55-67. doi: 10.1080/0729436970160105

National Union of Students. (2008). Mark my words, not my name. The campaign for anonymous marking. http://www.nus.org.uk/cy/news/mark-my-words-not-my-name/

Nyman, M. A., \& Berry, J. (2002). Developing transferable skills in undergraduate mathematics students through mathematical modelling. Teaching Mathematics and its Applications, 21(1), 29-45. doi: 10.1093/teamat/21.1.29

Meyer, J.H.F. and Land, (2005). Threshold Concepts and Troublesome Knowledge (2): Epistemological Considerations and a Conceptual Framework for Teaching and Learning. Higher Education, (49)3, 373-388, doi: 10.1007/s10734-004-6779-5

Mark, E. (2013). Student satisfaction and the customer focus in higher education. Journal of Higher Education Policy and Management, 35(1), 2-10, doi: 10.1080/1360080X.2012.727703

Munteanu, C., Ceobanu, C., Bobalca, C., \& Anton, O. (2010). An analysis of customer satisfaction in a higher education context. International Journal of Public Sector Management, 23, 124-140, doi:10.1108/09513551011022483 
Nelson, H. (2013). Testing more, teaching less: What America's obsession with student testing costs in money and lost instructional time. New York: American Federation of Teachers.

O'Donovan, B. (2010). Filling a pail or lighting a fire? The intellectual development of management undergraduates. International Journal of Management Education, 9(1), 1-10.

O'Donovan, B., Price, M., \& Rust, C. (2004). Know what I mean? Enhancing student understanding of assessment standards and criteria. Teaching in Higher Education, 9(3), 325-336, doi:10.1080/1356251042000216642

Perry, W.G. (1970). Forms of intellectual development in the college years. New York: Holt, Rhinehart and Winston.

Price, M. Handley, K., Millar, J., \& O'Donovan, B. (2010). Feedback all that effort, but what is the effect? Assessment and Evaluation in Higher Education, 35(3), 277-289, doi: 10.1080/02602930903541007

QAA. 2006. Code of practice for the assurance of academic quality and standards in higher education. Section 6: assessment of students. 2nd ed. Mansfield: Quality Assurance Agency.

Rust, C., Price, M., \& O'Donovan, B. (2003). Improving students' learning by developing their understanding of assessment criteria and processes. Assessment and Evaluation in Higher Education, 28(2),147-164, doi:10.1080/02602930301671

Ramsden, P. (1992). Learning to teach in higher education. London: Routledge.

Ryan S., \& Neumann, R. (2013). Interdisciplinarity in an era of new public management: a case study of graduate business schools. Studies in Higher Education, 38(2), 192-206, doi: 10.1080/03075079.2011.571669

Saljo, R. (1982). Learning and understanding: A study of difference in constructing meaning from a text. Goteborg, Sweden: Acta Universitatis Gothoburgensis. Goteborg Studies in Educational Sciences, No. 41.

Saljo, R. (1988). Learning in educational settings: Methods of inquiry. In P. Ramsden (Ed.), Improving learning: New perspectives (pp.32-48). London: Kogan Page.

Sandoval, W. A. (2009). In Defense of Clarity in the Study of Personal Epistemology. The Journal of the Learning Sciences, 18(1), 150-161. doi: 10.1080/10508400802581700

Schommer, M. (1994). Synthesizing epistemological belief research: tentative understandings and provocative confusions. Educational Psychology Review, 6(4), 293-319. doi: 10.1007/BF02213418 
Scott, S. (1999). The academic as service provider: Is the customer 'always right'? Journal of Higher Education Policy and Management 21, 193-202, doi:10.1080/1360080990210206

Shanahan M \& Meyer, J.H.F. (2006).The troublesome nature of a threshold concept in economics. In Meyer, J.H.F. \& Land, R. (Eds.), pp 100-114. London and New York: Routledge.

Snowden, G. (2012). Graduates: is a 2:1 the best qualification for landing a job?, The Guardian. 10th February

Stobart, G. (2008). Testing Times. Abingdon: Routledge.

Sturman, L. (2003). Teaching to the test: Science or intuition? Educational Research, 45, 261273. doi:10.1080/0013188032000137256

Tsinidou, M. Gerogiannis, V. \& Fitsilis, P. (2010). Evaluation of the factors that determine quality in higher education: an empirical study. Quality Assurance in Higher Education, 18(3), 227244, doi: 10.1108/09684881011058669

Van Rossum, E.J., \& Hamer, R. (2010). The meaning of learning and knowing. Rotterdam: Sense Publishers.

Words: 7980 